Syntax Literate : Jurnal Ilmiah Indonesia p-ISSN: 2541-0849

e-ISSN : 2548-1398

Vol. 4, No. 9 September 2019

\title{
KARTELISASI MEDIA MASSA DALAM MEMBANGUN SENTIMEN KEAGAMAAN PADA PEMILUKADA DKI JAKARTA TAHUN 2012
}

\author{
Nunu Jaenudin \\ Universitas Islam Al-Ihya (UNISA) Kuningan \\ Email: jahenudin007@gmail.com
}

\begin{abstract}
Abstrak
Penelitian ini berusaha menjelaskan seperti apa sentimen keagamaan yang dimainkan oleh media massa pada masa Pemilukada DKI Jakarta berlangsung dan bagaimana pola interkasi media massa dengan partai politik. Metode yang digunakan dalam penelitian ini adalah analisis isi yang masuk kedalam kajian penelitian kualitaif adapun teknik analisis isi berusaha menampilkan isi berita terkait sentimen keagamaan pada Pemilukada DKI Jakarta. dengan metode pengumpulan data analisis teks berita wawancara mendalam dan studi pustaka sedangkan obyek penelitain ini adalah surat kabar harian Pos Kota, surat kabar harian Rakyat Merdeka, dan tabloid Suara Islam. Melalui analisis isi difokuskan kepada isu sentimen keagamaa yang ada pada surat kabar di bulan Juli Agustus dan September perbedaan kepentingan terlihat kepada kepentingan politiknya. Surat kabar harian Pos Kota dalam pemberitaannya banyak memuat sentimen keagamaan, Pos Kota terlihat mendukung pasangan Fauzi Bowo dan Nachrowi Ramli, dilihat dari banyaknya porsi pemberitaannya, serta melakukan seranganserangan terhadap calon gubernur Jokowi dan Ahok sedangkan surat kabar harian Rakyat Merdeka pada putaran pertama mendukung pasangan Alex Nono dan pada putaran kedua lebih bersikap netral dengan berusaha menampilkan isu sentimen keagamaan agar tidak menyebar ke masyarakat, adapun tabloid Suara Islam yang merupakan tabloid islam pada putaran pertama mereka mandukung calon gubernur Hidayat Nur Wahid dengan alasan satu ideologi dengan mereka. Penelitian ini membuktikan bahwa media massa cetak tidak bisa lepas dari kepentingan pragmatisme politik dan juga idealisme media massa dalam konteks pemilihan umum kepala daerah (Pemilukada) DKI Jakarta ditingkat lokal. Kedepan penting dilihat kembali konsistensi konstruksi media cetak pada pemberitaan politik yang lain., sehingga dapat dilihat juga apakah konstruksi dapat dipengaruhi oleh isu yang berkembang dari sikap partai politik,.
\end{abstract}

Kata Kunci: Kartelisasi, Media Massa, Analisis Isi, Sentimen Keagamaan, Pemilihan Umum Kepala Daerah (Pemilukada), dan DKI Jakarta 


\section{Pendahuluan}

Peristiwa politik selalu menarik media massa sebagai bahan liputan. Hal ini terjadi karena dua faktor yang sering berkaitan. Pertama, dewasa ini politik berada di era mediasi yakni media massa, sehingga hampir mustahil kehidupan politik dipisahkan dari media massa. Malahan para aktor politik senantiasa berusaha menarik perhatian wartawan agar aktivitas politknya memperoleh liputan dari media. Kedua, peristiwa politik dalam bentuk tingkah laku dan pernyataan para aktor politik lazimnya selalu mempunyai nilai berita sekalipun peristiwa politik itu bersifat rutin belaka. Seumpamanya rapat partai atau pertemuan seorang tokoh politik dengan para pendukungnya. Apalagi jika peristiwa politik itu bersifat luar biasa seperti pergantian presiden di tengah masa jabatan dan pembubaran parlemen. Alhasil, liputan politik senantiasa menghiasi berbagai media setiap harinya (Hamad, 2004)

\section{Metode Penelitian}

Penelitian ini merupakan jenis penelitian kualitatif (Moleong \& Surjaman, 1991) Penelitian kualitatif digunakan untuk meneliti kondisi obyek yang alamiah, dimana peneliti adalah sebagai instrumen kunci, teknik pengumpulan data dilakukan secara triangulasi (gabungan), analisa data bersifat induktif atau kualitatif, dan hasil penelitian kualitatif lebih menekankan makna dari pada generalisasi (Amrullah \& Waryana, 2019). Penggunaan metode analisis isi (Content Analysis) secara sederhana diartikan sebagai metode untuk mengumpulkan dan menganalisis muatan dari sebuah "teks". Teks dapat berupa kata-kata, makna gambar, simbol, gagasan, tema, dan bermacam bentuk pesan yang dapat dikomunikasikan. Analisis Isi berusaha memahami data bukan sebagai kumpulan peristiwa fisik, melainkan sebagai gejala simbolik untuk mengungkap makna yang terkadang dalam sebuah teks, dan memperoleh pemahaman terhadap pesan yang direpresentasikan (Bell, 2001). Sesuai tujuannya, metode Analisis isi menjadi pilihan untuk diterapkan pada penelitian yang terkait dengan isi komunikasi dalam sebuah teks. Ada beberapa pertanyaan tipikal yang dapat dijawab dengan menggunakan metode Analisis isi, yaitu pertanyaan tentang prioritas hal penting dari isi teks, seperti frekuensi, dimensi, aturan dan jenis-jenis citra atau cerita dari peristiwa yang direpresentasikan. Pertanyaan tentang "bias" informasi dalam teks, seperti komparasi 
relatif tentang durasi, frekuensi, prioritas, atau hal yang ditonjolkan dalam berbagai representasi. Perubahan historis dalam modus representasi.

Penelitian analisis isi berusaha melihat konsistensi makna dalam sebuah teks. Konsistensi ini dapat dijabarkan dalam pola-pola terstruktur yang dapat membawa peneliti kepada pemahaman tentang sistem nilai dibalik teks itu. Metode Analisis isi menuntut beberapa persyaratan: objektif, sistematis, dan dapat digeneralisasikan. Objektif berarti prosedur dan kriteria pemilihan data, pengkodean serta cara interpretasi harus didasarkan pada aturan yang telah ditentukan sebelumnya. Sistematis berarti inklusi dan ekslusi atau kategori harus berdasarkan aturan yang konsisten. Dapat digeneralisasikan, berarti tiap temuan harus memiliki relevansi teoretis (Newman, 1991) menyebutkan langkah-langkah dalam meneliti dengan metode Analisis Isi, yaitu (1) menentukan unit analisis (misalnya jumlah teks yang ditetapkan sebagai kode), (2) menentukan sampling (3) menentukan variabel dan menyusun kategori pengkodean, dan (5) menarik kesimpulan.

\section{Hasil dan Pembahasan}

\section{A. Konstruksi Media Terhadap Realitas}

Produk manusia tidak dapat dilepaspisahkan dengan dan dari konteks sosio historis dan kultural di mana realitas itu berada. Setiap aktivitas manusia memiliki pesan-pesan tertentu berdasarkan konteksnya. Pada kajian media massa hal ini menjadi beragam. Pada media cetak misalnya tercermin pada sikap dan kognisi sosial wartawan.

Oleh sebab itu, dalam memahami cara kerja media merekam dan mengkonstruksi sebuah fakta, penting pula untuk menelaah bagaimana media menangkap realitas dibalik pemberitaan. Dari proses pencarian, pengumpulan dan penyampaian pesan (realitas) semuanya melibatkan agen pengkostruksi, dalam hal ini adalah wartawan. Media mengikutsertakan perspektif dan cara pandang mereka dalam menafsirkan realitas sosial (Berger \& Luckmann, 1991).

\section{B. Bahasa Media Massa}

Pemakaian bahasa Indonesia dalam media massa sudah semakin luas, bahkan membentuk genre sendiri, yakni bahasa Indonesia jurnalistik. Bahsa-bahasa di media massa dimanfaatkan oleh berbagai pihak untuk berbagai kepentingan. 
Secara umum pembaca media massa berkepentingan untuk memperoleh informasi baru. Dalam praktiknya, bahasa dipergunakan untuk beragam keperluan dan disajikan melalui berbaggai media massa. Kepentinagn tersebut menyebabkan pemakai bahasa membungkus kepentigan dalam bahasa yang disajikan. Dalam posisi ini bahasa dipahami sebagai medium yang tidak bebas, mengikuti kepentingan pemakainya, kajian bahasa yang menyertakan aspek kepentingan (ideologi) pemakainya sering dipergunakan untuk mengungkapkan apa ideologi yang tersimpan di balik teks tersebut.

1. Pemberitaan Surat Kabar Harian Pos Kota Dalam Mengkonstruki Sentimen Keagamaan

Farmat berita Pemilukada DKI Jakarta 2012 bahwa isu SARA itu menarik perhatian masyarkat bahwa isu itu perlu di selesaikan bahwa isu tersebut perlu ada solusi Pos Kota menyatukan bahwa bagaimana isu itu di kemas tapi tidak menimbulkan perpecahan.

a) Pemberitaan Surat Kabar Harian Pos Kota Bulan Juli 2012

Tabel 1.

Pemberitaan Surat Kabar Harian Pos Kota Bulan Juli 2012

\begin{tabular}{|c|c|c|c|}
\hline No & Tanggal & Judul & Keterangan \\
\hline 1 & 1 Juli 2012 & $\begin{array}{c}\text { Warga NU Harus } \\
\text { Cerdas Pilih Gubernur }\end{array}$ & $\begin{array}{l}\text { Pilihlah pemimpin } \\
\text { mementingkan wang } \\
\text { tersebut disampaikaan Foke terkait } \\
\text { adanya salah satu cagub yang } \\
\text { meninggalkan warganya hanya untuk } \\
\text { mengejar ambisi menjadi gubernur } \\
\text { DKI Jakarta }\end{array}$ \\
\hline 2 & 6 Juli 2012 & $\begin{array}{c}\text { Foke-Nara Mampu Jaga } \\
\text { Kerukunan Umat }\end{array}$ & $\begin{array}{l}\text { Pasangan calon gubernur dan wakil } \\
\text { gubernur Fauzi Bowo-Nachrowi } \\
\text { Ramli (Foke-Nara) dinilai sosok yang } \\
\text { mumpuni menjaga kerukunan umat } \\
\text { beragama dan etnis ibukota }\end{array}$ \\
\hline 3 & 17 Juli 2012 & $\begin{array}{l}\text { "Gubernur Harus } \\
\text { Jaga Amanah" }\end{array}$ & $\begin{array}{l}\text { Menjadi gubernur itu harus jaga } \\
\text { amanah warga dan atas ridlo Allah } \\
\text { SWT, maka itu pula harus dijaga } \\
\text { jangan meninggalkan amanah yang } \\
\text { sudah diberikan kepada kita }\end{array}$ \\
\hline 4 & 21 Juli 2012 & $\begin{array}{c}\text { Foke Kecam } \\
\text { Penghembus Isu SARA } \\
\text { Di Pemilukada }\end{array}$ & $\begin{array}{l}\text { Fauzi Bowo mengecam keras soal isu } \\
\text { SARA yang dihembuskan dalam } \\
\text { Pilkada DKI } 2012 \text { dia menegaskan } \\
\text { isu SARA sangat bertentangan } \\
\text { dengan UUD 1945 }\end{array}$ \\
\hline
\end{tabular}




\begin{tabular}{|c|c|c|c|}
\hline 5 & 24 Juli 2012 & $\begin{array}{l}\text { Panwaslu Awasi } \\
\text { "Kampanye Hitam" }\end{array}$ & $\begin{array}{l}\text { Kampanye negatif (negattive } \\
\text { campaign) diprediksi bakal marak di } \\
\text { pelaksanaan pemilukada DKI Jakarta } \\
\text { putaran kedua }\end{array}$ \\
\hline 6 & 27 Juli 2012 & $\begin{array}{c}\text { Penghembus Isu SARA } \\
\text { di Pemilukada diancam } \\
\text { dipenjara }\end{array}$ & $\begin{array}{l}\text { Panitia Pengawas Pemilu (Panwaslu) } \\
\text { DKI Jakarta siap memenjarakan } \\
\text { siapapun penghembus isu SARA } \\
\text { pada pelaksanaan pemilihan umum } \\
\text { kepala daerah (Pemilukada) putaran } \\
\text { kedua }\end{array}$ \\
\hline 7 & 29 Juli 2012 & $\begin{array}{c}\text { Tim Sukses Jangan } \\
\text { Tebar Isu SARA }\end{array}$ & $\begin{array}{l}\text { Isu suku, agama, ras, dan antar } \\
\text { golongan (SARA) masih mewarnai } \\
\text { Pemilukada putaran kedua Panwaslu } \\
\text { DKI Jakarta mengingatkan agar tim } \\
\text { sukses kedua pasangan calon ikut } \\
\text { mengawasinya }\end{array}$ \\
\hline 8 & 30 Juli 2012 & $\begin{array}{l}\text { Gubernur: Mari Jaga } \\
\text { Ketenangan JAKARTA }\end{array}$ & $\begin{array}{l}\text { Fauzi Bowo mengajak umat untuk } \\
\text { menjaga ketenangn Jakarta } \\
\text { sedangkan Rhoma Irama mengajak } \\
\text { warga Jakarta untuk memilih } \\
\text { pemimpin yang seiman sesuai ajaran } \\
\text { Alquran }\end{array}$ \\
\hline
\end{tabular}

b) Pemberitaan Surat Kabar Harian Pos Kota Bulan Agustus 2012

Tabel 2.

Pemberitaan Surat Kabar Harian Pos Kota Bulan Agustus 2012

\begin{tabular}{|c|c|c|c|}
\hline No & Tanggal & Judul & Keterangan \\
\hline 1 & $\begin{array}{l}1 \text { Agustus } \\
2012\end{array}$ & $\begin{array}{l}\text { Jimly Asshiddiqie: Asal } \\
\text { Untuk Transparansi dan } \\
\text { Informasi Isu SARA } \\
\text { Dibolehkan Di pilkada }\end{array}$ & $\begin{array}{l}\text { Isu terkait suku, adat, ras, dan agama } \\
\text { tidak perlu dipersoalkan pada } \\
\text { pemilukada sepanjang digunakan } \\
\text { untuk transparansi dan memberikan } \\
\text { informasi kepada masyarakat }\end{array}$ \\
\hline 2 & $\begin{array}{l}2 \text { Agustus } \\
2012\end{array}$ & $\begin{array}{l}\text { Ribuan Warga Buka } \\
\text { Bersama BMFBNR } \\
\text { "Pilih pemimpin } \\
\text { Jakarta yang } \\
\text { amanah" }\end{array}$ & $\begin{array}{l}\text { Tokoh ulama mampang prapatan KH } \\
\text { Yusuf Sashi dalam ceramahnya } \\
\text { mengemukakan kehidupan umat } \\
\text { muslim sepenuhnya diatus sesuai } \\
\text { alquran terkait keberadaan seorang } \\
\text { pemimpin harus sesuai akidah agama } \\
\text { islam }\end{array}$ \\
\hline 3 & $\begin{array}{l}3 \text { Agustus } \\
2012\end{array}$ & $\begin{array}{l}\text { Suhu Politik Putaran } \\
\text { Kedua Mulai Panas }\end{array}$ & $\begin{array}{l}\text { Memasuki pemilukada putaran kedua } \\
\text { suhu politik di ibukota mulai } \\
\text { memanas. Berbagai atribut berupa } \\
\text { baliho bernuansa suku, agama, ras, } \\
\text { dan antar golongan (SARA) makin } \\
\text { musah ditemui di tiap wilayah } \\
\text { panwaslu sita } 53 \text { spanduk bermuatan } \\
\text { SARA di Jakut dan Jaksel }\end{array}$ \\
\hline
\end{tabular}




\begin{tabular}{|c|c|c|c|}
\hline 4 & $\begin{array}{l}4 \text { Agustus } \\
2012\end{array}$ & $\begin{array}{l}\text { MUI Imbau Warga tak } \\
\text { Salah Pilih Gubernur } \\
\text { "Cari Pemimpin yang } \\
\text { Seiman" }\end{array}$ & $\begin{array}{l}\text { MUI kecamatan Jagaskara, Jakarta } \\
\text { Selatan mengingatkan agar } \\
\text { masyarakat tidak salah menentukan } \\
\text { pilihannya pada pemilukada DKI } \\
\text { Jakarta } 2012 \text { carilah pemimpin yang } \\
\text { se-iman, amanah, jujur, adil, dan } \\
\text { aspiratif terhadap kebutuhan warga }\end{array}$ \\
\hline & $\begin{array}{l}4 \text { Agustus } \\
2012\end{array}$ & $\begin{array}{c}\text { Fauzi Ajak Jaga } \\
\text { Keamanan dan } \\
\text { Kedamaian "Jangan } \\
\text { terpancing isu SARA" }\end{array}$ & $\begin{array}{l}\text { Fauzi Bowo mengajak seluruh warga } \\
\text { DKI Jakarta agar tak mudah } \\
\text { terpancing dengan isu yang } \\
\text { dihembuskan pihak tertentu berkaitan } \\
\text { dengan SARA belakangan ini. }\end{array}$ \\
\hline 5 & $\begin{array}{l}5 \text { Agustus } \\
2012\end{array}$ & $\begin{array}{c}\text { Surya Dharma Ali: } \\
\text { Kader Mbalelo Kena } \\
\text { Sanksi } \\
\text { PPP Putuskan } \\
\text { Dukungan Foke-Nara }\end{array}$ & $\begin{array}{l}\text { Menurut SDA pemberian dukungan } \\
\text { kepada Foke-Nara didasarkan atas } \\
\text { berbagai pertimbangan salah satunya } \\
\text { adalah Foke-Nara merupakan sosok } \\
\text { cagub dan cawagub dari sisi religius } \\
\text { tidak diragukan lagi. }\end{array}$ \\
\hline 6 & $\begin{array}{l}7 \text { Agustus } \\
2012\end{array}$ & $\begin{array}{l}\text { Warga Ibukota harus } \\
\text { Jeli Pilih Gubernur }\end{array}$ & $\begin{array}{l}\text { Ketua komisi E DPRD DKI Jakarta, } \\
\text { yang membidangi } \\
\text { kesejahteraan masyarakat. } \\
\text { Firmansyah, sah-sah saja jika warga } \\
\text { ibukota ingin mencoba sosok baru } \\
\text { dalam memimpin kota ini. namun ia } \\
\text { berharap warga dapat meluangkan } \\
\text { waktu untuk mempelajari program } \\
\text { kerja yang akan diambil oleh setiap } \\
\text { kandidat. }\end{array}$ \\
\hline & $\begin{array}{l}7 \text { Agustus } \\
2012\end{array}$ & $\begin{array}{c}\text { Fauzi Bowo Buka } \\
\text { Bersama di Kebayoran } \\
\text { Baru } \\
\text { DKI perhatikan } \\
\text { kesehatan Ulama dan } \\
\text { Umaro }\end{array}$ & $\begin{array}{l}\text { Fauzi bowo mengatakan Ulama dan } \\
\text { tokoh masyarakat merupakan } \\
\text { panutan yang harus mendapatkan } \\
\text { perhatian pemerintah termasuk dalam } \\
\text { pembangunan ibukota untuk itu } \\
\text { pemprov DKI Jakarta memberikan } \\
\text { jaminan kesehatan untuk biaya rawat } \\
\text { inap atau operasi karena tak semua } \\
\text { ulama mampu berobat jika sakit. }\end{array}$ \\
\hline & $\begin{array}{l}7 \text { Agustus } \\
2012\end{array}$ & $\begin{array}{l}\text { Rhoma Irama Berikan } \\
\text { Keterangan di Panwaslu } \\
\text { "Apakah } \\
\text { Menyampaikan Ayat } \\
\text { AlQuran di Masjid itu } \\
\text { SARA?" } \\
\end{array}$ & $\begin{array}{l}\text { Raja dangdut sekaligus dai kondang } \\
\text { Rhoma Irama, menegaskan bahwa } \\
\text { menyampaikan ayat kitab suci } \\
\text { dirumah ibadah bukanlah sebuah } \\
\text { kesalahan }\end{array}$ \\
\hline 7 & $\begin{array}{l}9 \text { Agustus } \\
2012\end{array}$ & $\begin{array}{l}\text { Gubernur Diundang } \\
\text { Pendeta ke Gereja } \\
\text { Mawar Saron "Jakarta } \\
\text { Tak Punya Ruang } \\
\text { Untuk Isu SARA" }\end{array}$ & $\begin{array}{l}\text { Ungkapan keprihatinan diungkapkan } \\
\text { Fauzi Bowo pada pertemuan dengan } \\
\text { para pendeta dari seluruh DKI } \\
\text { Jakarta dan umat nasrani. Gubernur } \\
\text { pun mengajak seluruh lapisan }\end{array}$ \\
\hline
\end{tabular}




\begin{tabular}{|c|c|c|c|}
\hline & & & $\begin{array}{l}\text { masyarakat di ibukota bersama-sama } \\
\text { menjaga dan menciptakan } \\
\text { kedamaian. }\end{array}$ \\
\hline 8 & $\begin{array}{l}10 \text { Agustus } \\
2012\end{array}$ & $\begin{array}{c}\text { Bahas isu SARA } \\
\text { Panwaslu undang TK } \\
\text { dan Anas }\end{array}$ & $\begin{array}{l}\text { Isu SARA yang berhembus di Jakarta } \\
\text { menjelang pemilukada putaran ke } \\
\text { dua menjadi maslah serius yang } \\
\text { harus segera diatasi. }\end{array}$ \\
\hline \multirow[t]{2}{*}{9} & $\begin{array}{l}11 \text { Agustus } \\
2012\end{array}$ & $\begin{array}{l}\text { Deklarasi di Basmol } \\
\text { Kelurahan Kembangan } \\
\text { Utara Ulama se- } \\
\text { Jakarta Barat dukung } \\
\text { Foke-Nara }\end{array}$ & $\begin{array}{l}\text { Ulama se-Jakarta Barat } \\
\text { mendeklarasikan mendukung Foke- } \\
\text { Nara deklarasi itu ditunjukkan } \\
\text { kepada umat islam yang berada di } \\
\text { wilayah Jakarta Barat forum ulama } \\
\text { Jakbar memandang memilih } \\
\text { pemimpin berdasarkan laquran yakni } \\
\text { seiman seaqidah }\end{array}$ \\
\hline & $\begin{array}{l}11 \text { Agustus } \\
2012\end{array}$ & $\begin{array}{c}\text { Walikota ajak } \\
\text { masyarakat redam isu } \\
\text { SARA Tingkatkan } \\
\text { ukhuwah Islamiyah }\end{array}$ & $\begin{array}{l}\text { Suhu politik di ibukota memasuki } \\
\text { pemilukada putaran kedua mulai } \\
\text { memanas para alim ulama umat } \\
\text { islam di Jakarta utara diminta } \\
\text { meningkatkan ukhuwah islamiyah }\end{array}$ \\
\hline 10 & $\begin{array}{l}14 \text { Agustus } \\
2012\end{array}$ & $\begin{array}{c}\text { Ulama \& Habib } \\
\text { syukuran di Kwitang }\end{array}$ & $\begin{array}{l}\text { Para ulama dan habib se-DKI Jakarta } \\
\text { syukuran di Islamic Centre mereka } \\
\text { meminta kepada panwaslu DKI } \\
\text { Jakarta untuk tidak menakut-nakuti } \\
\text { para ulama yang memberikan } \\
\text { ceramah dikaitkan dengan isu SARA }\end{array}$ \\
\hline 11 & $\begin{array}{l}27 \text { Agustus } \\
2012\end{array}$ & $\begin{array}{l}\text { Fauzi Bowo Ahli } \\
\text { Benahi Jakarta }\end{array}$ & $\begin{array}{l}\text { Kalau cari pemipin itu serahkan ke } \\
\text { ahlinya nah itu sunnah rasul kalau } \\
\text { ngk ahli ngk usah dipilih kalau tidak } \\
\text { diserahkan ke ahlinya bisa hancur } \\
\text { kata Marzuki Ali. Marzuki ali juga } \\
\text { mengingatkan kriteria pemimpin } \\
\text { berdasarkan islam addalah pemimpin } \\
\text { yang tidak kafir yaitu pemimpin yang } \\
\text { seiman. }\end{array}$ \\
\hline
\end{tabular}

c) Pemberitaan Surat Kabar Harian Pos Kota Bulan September 2012

Tabel 3.

Pemberitaan Surat Kabar Harian Pos Kota Bulan September 2012

\begin{tabular}{ccll}
\hline No & Tanggal & \multicolumn{1}{c}{ Judul } & \multicolumn{2}{c}{ Keterangan } \\
\hline 1 & 1 September & Foke Ajak Warga, & Menjelang pemilukada DKI Jakrta \\
& 2012 & Ulama, dan Umaro & putaran ke dua kalangan ulama, \\
& & "Jaga Kampung Kita" & umaro dan seluruh masyarakat \\
& & diminta tetap kompak agar kota \\
& & Jakarta tetap kondusif Jakarta milik \\
& & & kita bersama mari kita sama-sama \\
& & & \\
& & &
\end{tabular}




\begin{tabular}{clll}
\hline & & dan masyarakat \\
\hline 2 & 3 September & Foke Bersama Massa & Fauzi Bowo berada di tengah ribuan \\
& PKS Konsolidasi dan & kader PKS dalam acara konsolidasi \\
& Halal bihalal & dan halal bihalal struktur dan \\
& & jaringan PKS se-Jakarta Selatan. \\
& & Triwicaksana menyerukan kepada \\
& & seluruh kadernya untuk bersatu. \\
& & Seluruh umat harus bersatu dan \\
& & jangan terkotak-kotak \\
\hline
\end{tabular}

3 September Gubernur DKI Dapat 2012 Gelar

Ketua umum Keluarga Besar Kerukunan Keluarga Sulawesi Selatan KKSS bapak Abdul Rifai mengatakan Fauzi Bowo sebagai orang kuat yang memiliki keteguhan dan keimanan serta memiliki kharisma dan tanggung jawab.

\begin{tabular}{cl}
\hline $4 \quad$ S September & Nara Halal bihalal \\
2012 & dengan Pemuda dan \\
& Ulama "Memimpin \\
& Jakarta tidak \\
& Gampang"
\end{tabular}

\section{September Hasyim Muzadi:} 2012 Dakwah Rhoma Irama tidak salah

\begin{tabular}{ccl}
\hline $6 \quad 7$ September & Wakil sekjen PKS. \\
2012 & Mahfudz Sidiq \\
& Penghembuh SARA \\
& Rusak Kerukunan
\end{tabular}

\begin{tabular}{ccl}
\hline 7 & 11 & GP Ansor DKI Minta \\
& $\begin{array}{c}\text { September } \\
2012\end{array}$ & Rhoma Irama Jangan \\
& Dikriminalisasi
\end{tabular}

Jakarta harus dijaga agar tetap nyaman dan sejahtera kata bang Nara sapaan akrab Nachrowi Ramli dalam acara halal bihalal dengan tokoh pemuda, masyarakat dan alim ulama dari berbagai elemen

Menurut Hasyim, Rhoma Irama
hanya menyarankan dalam dakwahnya, bahwa sebagai umat muslim harus begini dan begitu sesuai dengan ajaran islam
Menurutnya jika ada pihak yang menyampaikan ajaran agamanya sesuai dengan firman tuhannya dianggap melakukan tindakan SARA, justru sangat menyakitkan. Islam yang mengajarkan umatnya untuk memilih pemimpin dengan kriteria seorang mikmin.

Dukungan kepada raja dangdut yang juga dai. Rhoma Irama terus bermunculan dari berbagai kalangan pasca pemanggilan oleh panwaslu DKI Jakarta terkait isu SARA awal pekan lalu. Salah satunya datang dari Gerakan Pemuda (GP) Anshor yang menginduk ke Nahdlatul Ulama

\begin{tabular}{ccll}
\hline 8 & 13 & Ulama diminta beri & Walikota Jakarta Timur krisdianto \\
peptember & pencerahan soal & $\begin{array}{l}\text { mengingatkan agar memilih } \\
\text { pemimpin harus berdasarkan }\end{array}$ \\
& Wemilukada Ajak & $\begin{array}{l}\text { Warga jangan golput } \\
\text { kualitas, integritas, semangat juang } \\
\text { dan militansinya. Kepemimpinannya }\end{array}$ \\
\hline
\end{tabular}




\begin{tabular}{|c|c|c|c|}
\hline & & & $\begin{array}{l}\text { sebagai ibadah sekaligus amanah } \\
\text { suci sepenuh hati. }\end{array}$ \\
\hline \multirow[t]{2}{*}{9} & $\begin{array}{c}19 \\
\text { September } \\
2012\end{array}$ & $\begin{array}{l}\text { Jangan terjebak } \\
\text { Wacana Tak Jelas }\end{array}$ & $\begin{array}{l}\text { Forum masyarakat tionghoa (Format) } \\
\text { mengajak warga tionghoa jakarta } \\
\text { untuk berfikir cerdas dan bijak dalam } \\
\text { memilih pemimpin janagn sampai } \\
\text { terjebak oleh wacana-wacana yang } \\
\text { tak jelas }\end{array}$ \\
\hline & $\begin{array}{c}19 \\
\text { September } \\
2012\end{array}$ & $\begin{array}{l}\text { Tatiek Fauzi Bowo } \\
\text { Ziarah Kemakam } \\
\text { Orangtua } \\
\text { Solo Simpan Sejuta } \\
\text { Kenangan }\end{array}$ & $\begin{array}{l}\text { Bagi Hj Tatiek Fauzi Bowo, Solo } \\
\text { merupakan kota yang menyimpan } \\
\text { sejuta kenangan dalam hidupnya } \\
\text { bagaimana tidak? Meski lahir di } \\
\text { Semarang Istri gubernur DKI ini } \\
\text { banyak menghabiskan masa kecilnya } \\
\text { di kota ini. Wajar saja mengingat } \\
\text { kedua orangtuanya asli berasal dari } \\
\text { Solo }\end{array}$ \\
\hline
\end{tabular}

2. Pemberitaan Surat Kabar Harian Rakyat Merdeka Dalam Mengkonstruki Sentimen Keagamaan

Isu agama yang muncul dalam pemberitaan media-media, termasuk Rakyat Merdeka, bukan dalam konteks pemberitaan yang sifatnya memojokkan atau menyerang salah satu pihak. Rakyat Merdeka "memotret" realita, yaitu tanggapan dan efek isu SARA terhadap masyarakat di DKI Jakarta.

a) Pemberitaan Surat Kabar Harian Rakyat Merdeka Bulan Juli 2012

Tabel 4.

Pemberitaan Surat Kabar Harian Rakyat Merdeka Bulan Juli 2012

\begin{tabular}{|c|c|c|c|}
\hline No & Tanggal & Judul & Keterangan \\
\hline 1 & 2 Juli 2012 & $\begin{array}{l}\text { Survei LSI Ngaku } \\
\text { Dibayari Foke }\end{array}$ & $\begin{array}{l}\text { Lingkaran Survei Indonesia (LSI) } \\
\text { akhirnya mengaku bahwa surveinya } \\
\text { dalam pemilihan gubernur DKI } \\
\text { jakarta didanai calon no 1. Foke- } \\
\text { Nara. Sejak pertama, LSI sudah } \\
\text { dikontrak Foke-Nara sebagai } \\
\text { konsultan politik }\end{array}$ \\
\hline & 2 juli 2012 & $\begin{array}{c}\text { Profil Alex-Nono } \\
\text { Mengemban Amanah } \\
\text { Dipercaya Negara dan } \\
\text { Masyarakat }\end{array}$ & $\begin{array}{l}\text { H. Alex Noerdin pernah dipercaya } \\
\text { menjadi Chef de Mission dan } \\
\text { komandan kontingen Republik } \\
\text { Indonesia pada Sea Games } 2009 \text { di } \\
\text { Laos. Kepercayaan negara tersebut } \\
\text { diberikan karena pengalamannya } \\
\text { yang sudah malang melintang dilebih } \\
\text { dari } 24 \text { organisasi olahraga, asosiasi } \\
\text { proffesi, pemerintahaan, dan }\end{array}$ \\
\hline
\end{tabular}




\begin{tabular}{|c|c|c|c|}
\hline & & & kemasyarakatan \\
\hline 2 & 4 Juli 2012 & $\begin{array}{c}\text { Omongan Bau SARA } \\
\text { Sulit Dilupakan Warga } \\
\text { Jokowi-Ahok Kurang } \\
\text { Faham Suasana } \\
\text { Kebatinan Jakarta }\end{array}$ & $\begin{array}{l}\text { Duet Jokowi-Ahok dikritik warga } \\
\text { Jakartra. Ada pandangan dari } \\
\text { pasangan cagub-cawagub ini dirasa } \\
\text { kurang enak didengar. Selain berbau } \\
\text { SARA, juga dinilai bernuansa } \\
\text { sekuler. Keduanya belum mampu } \\
\text { membaca situasi batin warga }\end{array}$ \\
\hline 4 & 20 Juli 2012 & $\begin{array}{c}\text { Pandangan Politisi } \\
\text { Demokrat, Achmad } \\
\text { Mubarok: Penggunaan } \\
\text { Isu SARA di Pilkada } \\
\text { Tidak Haram }\end{array}$ & $\begin{array}{l}\text { Ahmad Mubarok, anggota Dewan } \\
\text { Pembina partai Demokrat yang juga } \\
\text { pendukung pasangan Foke-Nara, } \\
\text { punya pendapat sendiri soal } \\
\text { penggunaan isu SARA. Menurut dia, } \\
\text { penggunaan SARA di pilkada Jakarta } \\
\text { bukanlah barang haram, jadi tidak } \\
\text { mengapa }\end{array}$ \\
\hline 5 & 24 Juli 2012 & $\begin{array}{c}\text { Ahok Terbiasa } \\
\text { Diserang SARA Sejak } \\
\text { Tahun } 2005\end{array}$ & $\begin{array}{l}\text { Calon wakil gubernur DKI Jakarta, } \\
\text { Basuki Tjahja Purnama atau yang } \\
\text { lebih akrab dipanggil Ahok, angkat } \\
\text { bicara soal gelombang isu suku, } \\
\text { agama, ras, dan antargolongan } \\
\text { (SARA) yang menyerang kubunya }\end{array}$ \\
\hline 6 & 25 Juli 2012 & $\begin{array}{l}\text { Isu SARA Merebak, } \\
\text { Politik Mundur Ke Era } \\
200 \text { Tahun Lalu }\end{array}$ & $\begin{array}{l}\text { Guru Besar Psikologi Politik UI } \\
\text { Hamdi Muluk menyayangkan } \\
\text { massifnya isu suku, agama, ras, dan } \\
\text { antargolongan (SARA) menjelang } \\
\text { putaran kedua pilkada DKI Jakarta } \\
\text { "Politik Indonesia seperti mundur } \\
200 \text { tahun lalu" }\end{array}$ \\
\hline 7 & 26 Juli 2012 & $\begin{array}{l}\text { Pilkada Putaran 2, } \\
\text { Cagub Akan Saling } \\
\text { Menjatuhkan }\end{array}$ & $\begin{array}{l}\text { Direktur Perkumpulan Untuk Pemilu } \\
\text { dan Demokrasi (Perludem), Titi } \\
\text { Anggraeni, menegaskan memasuki } \\
\text { putaran kedua Pilkada DKI Jakarta } \\
\text { isu yang bernuansa menjatuhkan } \\
\text { lawan politik kian gencar }\end{array}$ \\
\hline 8 & 30 Juli 2012 & $\begin{array}{l}\text { Puaran Dua Pilkada } \\
\text { DKI, Isu SARA Makin } \\
\text { Masif Polisi Didesak } \\
\text { Ikut Awasi }\end{array}$ & $\begin{array}{l}\text { Memasuki putaran kedua Pilkada } \\
\text { DKI Jakarta, peredaran isu SARA } \\
\text { bakal makin marak. Isu SARA } \\
\text { ditebar untuk mendeligitimasi } \\
\text { pasangan cagub-cawagub. Kemasaan } \\
\text { peredaran isu SARA-nya pun makin } \\
\text { rapi. Warga diharapkan tidak mudah } \\
\text { terpancing dan berani melaporkan } \\
\text { peredaran isu SARA }\end{array}$ \\
\hline 9 & 30 Juli 2012 & $\begin{array}{c}\text { SARA \& Pemilih } \\
\text { Rasional }\end{array}$ & $\begin{array}{l}\text { SARA yang sama ternyata tidak lebih } \\
\text { adil, korup, dan miskin komitmen } \\
\text { keadilan serta keberpihakan kepada } \\
\text { kelompoknya. SARA diusirnya jauh- }\end{array}$ \\
\hline
\end{tabular}




\begin{tabular}{|c|c|c|c|}
\hline & & & $\begin{array}{l}\text { jauh dalam kehidupan berpolitik. Di } \\
\text { Jakarta sepertinya sudah mulai terjadi } \\
\text { dan indikasinya suddah mulai terbaca } \\
\text { dengan jelas }\end{array}$ \\
\hline 10 & 30 Juli 2012 & $\begin{array}{c}\text { Di Acara Buka } \\
\text { Bersama PD Pasar jaya } \\
\text { Ustadz Ajak Warga } \\
\text { Pilih Pemimpin yang } \\
\text { Seiman }\end{array}$ & $\begin{array}{l}\text { Ustadz Zulfam Musthofa yang } \\
\text { memberikan ceramah kultum tanpa } \\
\text { tedeng aling-aling mengajak para } \\
\text { jamaah yang mengahdiri acara } \\
\text { tersebut agar memilih pemimpin yang } \\
\text { seiman dan seakidah di puatarn dua } \\
\text { pilkada DKI Jakarta }\end{array}$ \\
\hline \multirow[t]{3}{*}{11} & 31 Juli 2012 & Jimly: Isu SARA & Ketua Dewan Kehorrmatan \\
\hline & & $\begin{array}{c}\text { Boleh Digunakan Di } \\
\text { Pilkada DKI }\end{array}$ & $\begin{array}{l}\text { Penyelenggaraan Pemilu, Jimly } \\
\text { Asshiddiqie, tidak mengharramkan } \\
\text { isu SARA (Suku, Agama, Ras, dan } \\
\text { Antargolongan) di putaran dua } \\
\text { Pilkada Jakarta di lapangan, timses } \\
\text { cagub Foke maupun Jokowi, } \\
\text { jantungnya sama-sama dag-dig-dug } \\
\text { mendengar peredaran isu SARA }\end{array}$ \\
\hline & 31 Juli 2012 & $\begin{array}{l}\text { "Isu SARA Rugikan } \\
\text { Kita Semua Loh..." }\end{array}$ & $\begin{array}{l}\text { Anggota KPUD DKI Aminullah } \\
\text { mengungkapkan, isu SARA yang } \\
\text { berkembang saat ini tidak } \\
\text { menguntungkan siapapun. Malah } \\
\text { memperkeruh suasana. }\end{array}$ \\
\hline
\end{tabular}

b) Pemberitaan Surat Kabar Harian Rakyat Merdeka BulanAgustus 2012

Tabel 5.

Pemberitaan Surat Kabar Harian Rakyat Merdeka BulanAgustus 2012

\begin{tabular}{|c|c|c|c|}
\hline No & Tanggal & Judul & Keterangan \\
\hline 1 & $\begin{array}{l}2 \text { Agustus } \\
2012\end{array}$ & $\begin{array}{l}\text { Boleh-boleh Saja } \\
\text { Bicara SARA, Tapi } \\
\text { Jangan Menghina }\end{array}$ & $\begin{array}{l}\text { Ketua kelompok kerja (Pokja) } \\
\text { bidang kampanye KPUD Jakarta } \\
\text { Suhartono menghimbau masyarakat } \\
\text { lebih dewasa } \\
\text { penggunaan isu SARA. Masyarakat } \\
\text { tak perlu cepat menilai } \\
\text { pembicaraan SARA sebagai bentuk } \\
\text { penghinaa. Boleh } \\
\text { membicarakan SARA tapi tidak } \\
\text { boleh menghina }\end{array}$ \\
\hline 2 & $\begin{array}{l}2 \text { Agustus } \\
2012\end{array}$ & $\begin{array}{c}\text { Panwaslu Sekidiki } \\
\text { Video Ceramah } \\
\text { Rhoma Irama Diduga } \\
\text { Ungkit-Ungkit Isu } \\
\text { SARA }\end{array}$ & $\begin{array}{l}\text { Si Raja Dangdut, H Rhoma Irama, } \\
\text { terancam pidana dan denda jika } \\
\text { terbukti menghasut massa dengan } \\
\text { mengungkit suku atau agama dari } \\
\text { salah satu calon yang akan } \\
\text { mengikuti putaran dua pemilihan } \\
\text { gubernur DKI Jakarta }\end{array}$ \\
\hline
\end{tabular}




\begin{tabular}{|c|c|c|c|}
\hline \multirow[t]{3}{*}{3} & $\begin{array}{l}3 \text { Agustus } \\
2012\end{array}$ & $\begin{array}{c}\text { PPP Dukung Foke } \\
\text { Pakai Alasan Aqidah }\end{array}$ & $\begin{array}{l}\text { Ketua Umum PPP Surya Dharma } \\
\text { Ali (SDA), menjadikan aqidah dan } \\
\text { ideologi sebagai alasan utama } \\
\text { mendukung pasangan cagub- } \\
\text { cawagub nomor urut satu itu. "tapi } \\
\text { kita juga minta masalah aqidah } \\
\text { tidak dimaknai sempit". }\end{array}$ \\
\hline & $\begin{array}{l}3 \text { Agustus } \\
2012\end{array}$ & $\begin{array}{c}\text { Agar Isu SARA Tak } \\
\text { Menyulut Rusuh Di } \\
\text { Jakarta Taufik Kiemas } \\
\text { Siap Jadi Mediator } \\
\text { Jokowi-Foke }\end{array}$ & $\begin{array}{l}\text { Peredaran isu terkait Suku, Agama, } \\
\text { Ras dan Antargolongan (SARA) } \\
\text { para pasangan cagub-cawagub } \\
\text { Jakarta diputaran kedua Pilkada } \\
\text { Jakarta makin memprihatinkan. } \\
\text { Untuk meminimalisir peredaran isu } \\
\text { SARA Taufik siap jadi mediator } \\
\text { untuk mempertemukan Foke-Nara } \\
\text { dan Jokowi-Ahok }\end{array}$ \\
\hline & $\begin{array}{l}3 \text { Agustus } \\
2012\end{array}$ & $\begin{array}{l}\text { Kampanye Tidak } \\
\text { Mencerdaskan Bisa } \\
\text { Kontaraproduktif }\end{array}$ & $\begin{array}{l}\text { Pengamat politik LIPI Siti Zuhro } \\
\text { menyesalkan ceramah agama } \\
\text { bernuansa SARA. "Kampanye yang } \\
\text { tidak mencerdaskan justru akan } \\
\text { menuai hak yang negatif karena } \\
\text { tidak memberikan pelajaran yang } \\
\text { positif. }\end{array}$ \\
\hline \multirow[t]{5}{*}{4} & $\begin{array}{l}5 \text { Agustus } \\
2012\end{array}$ & $\begin{array}{l}\text { Pengusaha Ngeri } \\
\text { dengar isu SARA } \\
\text { Pilkada jakarta }\end{array}$ & $\begin{array}{l}\text { Ketua Himpunan Pengusaha Muda } \\
\text { Indonesia Sarman Simanjorang } \\
\text { mengatakan, pilkada Jakarta adalah } \\
\text { barometer bagi pilkada di provinsi } \\
\text { lain. Sebagai pelaku usaha dia } \\
\text { sangat berharap agar kondisi } \\
\text { Jakarta jelang pilkada dua tetap } \\
\text { kondusif. }\end{array}$ \\
\hline & $\begin{array}{l}5 \text { Agustus } \\
2012\end{array}$ & $\begin{array}{l}\text { Isu SARA Bikin Etnis } \\
\text { Tionghoa Bergairah }\end{array}$ & $\begin{array}{l}\text { Dari } 13.211 \text { pendaftar baru, setikar } \\
10 \text { ribuan yang berasal dari etnis } \\
\text { Tionghoa }\end{array}$ \\
\hline & $\begin{array}{l}5 \text { Agustus } \\
2012\end{array}$ & $\begin{array}{l}\text { Diserang isu SARA } \\
\text { Ahok Tak Khawatir }\end{array}$ & $\begin{array}{l}\text { Ahok yakin warga Jakarta sudah } \\
\text { cerdas dan tahu persis siapa pemain } \\
\text { dibelakang isu SARA itu. }\end{array}$ \\
\hline & $\begin{array}{l}5 \text { Agustus } \\
2012\end{array}$ & $\begin{array}{l}\text { Pilkada Harus Bentuk } \\
\text { Solidaritas Kebangsaan }\end{array}$ & $\begin{array}{l}\text { Pengamat politik Fadzroel } \\
\text { mengatakan, bukan hanya Fauzi } \\
\text { Bowo yang diduga bermain isu } \\
\text { SARA, Jokowi juga diduga ikut } \\
\text { bermain "permainan yang sedang } \\
\text { berlangsung diputaran dua pilkada } \\
\text { Jakarta sangat berbahaya". }\end{array}$ \\
\hline & $\begin{array}{l}5 \text { Agustus } \\
2012\end{array}$ & $\begin{array}{l}\text { Jimly Minta Panwaslu } \\
\text { Ngak “Gantung } \\
\text { Rhoma }\end{array}$ & \begin{tabular}{lcr} 
Ketua & dewan & \multicolumn{2}{c}{ kehormatan } \\
Penyelenggaraan pemilu & (DKPP), \\
Jimly Asshiddiqie akan & diperiksa \\
panitia & pengawas & pemilu
\end{tabular} \\
\hline
\end{tabular}




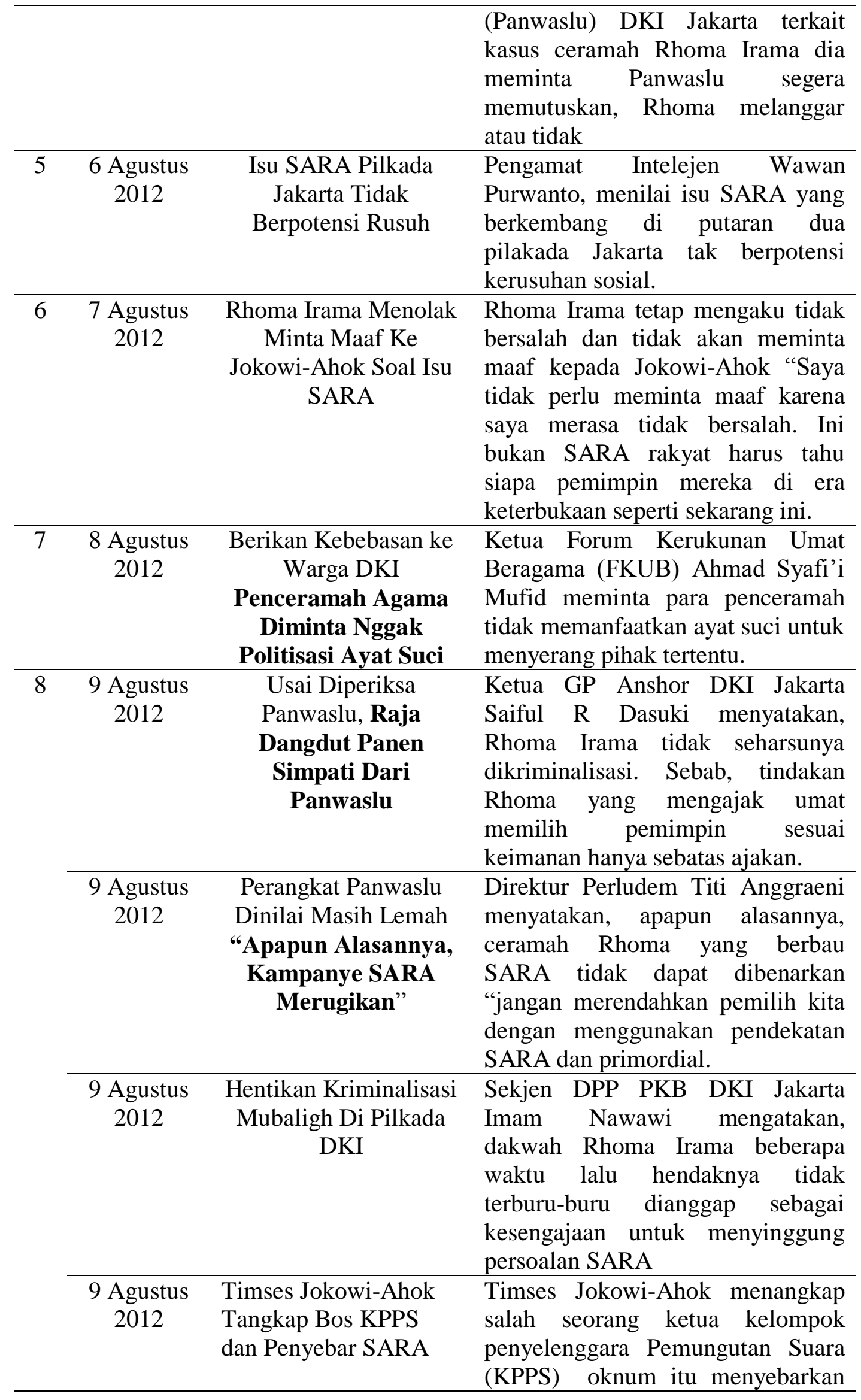




\begin{tabular}{|c|c|c|c|}
\hline & & & $\begin{array}{l}\text { buku-buku yang materinya } \\
\text { menyudutkan Jokowi-Ahok }\end{array}$ \\
\hline \multirow[t]{2}{*}{9} & $\begin{array}{l}10 \text { Agutus } \\
2012\end{array}$ & $\begin{array}{c}\text { Ceramah SARA } \\
\text { Rhoma Beredar Utak } \\
\text { Atik Agama Cagub } \\
\text { Dan kelauarganya }\end{array}$ & $\begin{array}{l}\text { Rekaman ceramah Rhoma Irama } \\
\text { sudah beredar luas dimasyarakat } \\
\text { tidak utuh hanya berupa potongan } \\
\text { video durasinya sekitar } 7 \text { menit } \\
\text { video ini sudah dikantongi } \\
\text { Panwaslu DKI Jakarta dan } \\
\text { dijadikan bukti dugaan pelanggaran }\end{array}$ \\
\hline & $\begin{array}{l}10 \text { Agutus } \\
2012\end{array}$ & $\begin{array}{c}\text { Buntut Pemeriksaan } \\
\text { Dugaan Kasus SARA } \\
\text { Rhoma Irama Banjir } \\
\text { Dukungan, Panwaslu } \\
\quad \text { Panen Kritikan } \\
\end{array}$ & $\begin{array}{l}\text { Dukungan terhadap Rhoma Irama } \\
\text { terus mengalir. Setelah PKB kini } \\
\text { PAN yang menyatakan mendukung } \\
\text { Rhoma sebagai pihak yang tidak } \\
\text { bersalah dalam Pilkada Jakarta }\end{array}$ \\
\hline \multirow[t]{5}{*}{10} & $\begin{array}{l}12 \text { Agustus } \\
2012\end{array}$ & $\begin{array}{l}\text { Jangan Perkeruh } \\
\text { Suasana Pilakada }\end{array}$ & $\begin{array}{l}\text { Polda Metro jaya mengimbau } \\
\text { jangan ada pihak yang } \\
\text { memperkeruh suasana dengan } \\
\text { memanfaatkan isu pemukulan } \\
\text { terhadap Yusuf (31) santri pondok } \\
\text { pesantren Riyadul Mukminin } \\
\text { Grogol Petamburan Jakarta Barat }\end{array}$ \\
\hline & $\begin{array}{l}12 \text { Agustus } \\
2012\end{array}$ & $\begin{array}{l}\text { Panwaslu Ajak Cagub } \\
\text { Redam Gejolak SARA }\end{array}$ & $\begin{array}{l}\text { Panwaslu DKI Jakarta berencana } \\
\text { mempertemukan para calon } \\
\text { gubernur, pertemuan bertujuan } \\
\text { untuk membicarakan penyebaran } \\
\text { isu SARA yang kian gencar }\end{array}$ \\
\hline & $\begin{array}{l}12 \text { Agustus } \\
2012\end{array}$ & $\begin{array}{l}\text { Terkait Pernyataan di } \\
\text { Depan Korban } \\
\text { Kebakaran Karet } \\
\text { Tengah Fauzi Bowo } \\
\text { Sama Saja Menghina } \\
\text { Warga }\end{array}$ & $\begin{array}{l}\text { Kecaman terhadap pernyataan } \\
\text { Fauzi Bowo didepan korban } \\
\text { kebakaran terus mengalir politisi } \\
\text { partai Gerindra Fadli Zon menilai } \\
\text { Foke tidak memiliki sensitifitas } \\
\text { terhadap warganya }\end{array}$ \\
\hline & $\begin{array}{l}12 \text { Agustus } \\
2012\end{array}$ & $\begin{array}{l}\text { Warga DKI Dihimbau } \\
\text { Tak Terbuai Janji } \\
\text { Berbau SARA Ruhut: } \\
\text { Pemilih Sudah Cerdas, } \\
\text { Tak Bisa Dibodohi }\end{array}$ & $\begin{array}{l}\text { Ketua DPP Partai Demokrat Ruhut } \\
\text { Sitompul menyatakan bahwa warga } \\
\text { Jakarta sudah pintar putaran ke dua } \\
\text { saya mengimbau warga Jakarta } \\
\text { jangan mau terbuai dengan janji- } \\
\text { janji apa lagi janji-janji yang } \\
\text { berbau SARA }\end{array}$ \\
\hline & $\begin{array}{l}12 \text { Agustus } \\
2012\end{array}$ & $\begin{array}{l}\text { Ahok: Isu Sara Sudah } \\
\text { Masa Lalu }\end{array}$ & $\begin{array}{l}\text { Menangggapi isu SARA Ahok } \\
\text { santai saja "masalah isu SARA } \\
\text { saya kira sudah masa lalu", dan } \\
\text { tidak jamannya lagi }\end{array}$ \\
\hline 11 & $\begin{array}{l}13 \text { Agustus } \\
2012\end{array}$ & $\begin{array}{l}\text { Panwaslu Tidak } \\
\text { Lanjutkan Kasus } \\
\text { Rhoma Ke Polisi }\end{array}$ & $\begin{array}{l}\text { Panwaslu tidak melanjutkan kasus } \\
\text { ini kepada kepolisian dalam } \\
\text { penyelidikan Panwaslu Rhoma } \\
\text { hanya menyampaikan identitas } \\
\text { pasangan calon gubernur DKI }\end{array}$ \\
\hline
\end{tabular}




\begin{tabular}{|c|c|c|c|}
\hline & & & $\begin{array}{l}\text { Jakarta pasangan yang masuk pada } \\
\text { putaran dua }\end{array}$ \\
\hline 12 & $\begin{array}{l}14 \text { Agustus } \\
2012\end{array}$ & $\begin{array}{c}\text { Tokoh Lintas Agama } \\
\text { Serukan Stop Pengguna } \\
\text { SARA }\end{array}$ & $\begin{array}{l}\text { Anggota Majelis Tinggi Agama } \\
\text { Konghucu Indonesia Ronny Ong } \\
\text { mengingatkan pemeluk agama } \\
\text { sama-sama saling menguatkan } \\
\text { iman agar tidak mudah terpengaruh } \\
\text { dengan isu SARA }\end{array}$ \\
\hline \multirow[t]{2}{*}{13} & $\begin{array}{l}15 \text { Agustus } \\
2012\end{array}$ & $\begin{array}{c}\text { Pengkuan Politisi } \\
\text { Gerindra \& PDIP Isu } \\
\text { SARA bakal Gerus } \\
\text { Perolehan Suara } \\
\text { Jokowi }\end{array}$ & $\begin{array}{l}\text { Isu SARA yang kerap } \\
\text { mengahantam } \\
\text { berpotensi menggerus perolehan } \\
\text { suara jago cagub-cawagub PDIP } \\
\text { dan Gerindra di putaran kedua } \\
\text { Pilkada Jakarta }\end{array}$ \\
\hline & $\begin{array}{l}15 \text { Agustus } \\
2012\end{array}$ & $\begin{array}{c}\text { Polda Metro Didesak } \\
\text { Tangkap Penybar Isu } \\
\text { SARA }\end{array}$ & $\begin{array}{l}\text { Koordinator Lingkar Madani Ray } \\
\text { Rangkuti meminta Panwaslu dan } \\
\text { Banwaslu Jakarta segera beraksi } \\
\text { dan memastikan isu SARA tidak } \\
\text { berkembang .dan segera } \\
\text { menggandeng polisi untuk melacak } \\
\text { pihak-pihak yang menybar isu } \\
\text { SARA }\end{array}$ \\
\hline \multirow[t]{3}{*}{14} & $\begin{array}{l}16 \text { Agustus } \\
2012\end{array}$ & $\begin{array}{c}\text { Wiranto Tak Suka Foke } \\
\text { Main SARA }\end{array}$ & $\begin{array}{l}\text { Wiranto agaknya ikut-ikutan gerah } \\
\text { melihat peredran isu SARA di } \\
\text { Pilkada Jakarta melalui Sekjen } \\
\text { partai Hanura Wiranto secara tidak } \\
\text { langsung mengingatkan kepada } \\
\text { Foke agar tidak memainkan isu } \\
\text { SARA di Pilkada Jakarta }\end{array}$ \\
\hline & $\begin{array}{l}16 \text { Agustus } \\
2012\end{array}$ & $\begin{array}{c}\text { Warning Budayawan } \\
\text { Ridwan Saidi Mainkan } \\
\text { SARA Persempit } \\
\text { Pemilih }\end{array}$ & $\begin{array}{l}\text { Budayawan Ridwan Saidi menilai } \\
\text { isu SARA tak akan efektif } \\
\text { mempengaruhi pemilih di Pilkada } \\
\text { DKI Jakarta Ridwan menganggap } \\
\text { pihak yang memainkan isu SARA } \\
\text { akan rugi sendiri }\end{array}$ \\
\hline & $\begin{array}{l}20 \text { Agustus } \\
2012\end{array}$ & $\begin{array}{c}\text { Hadir DI Acara } \\
\text { Peringatan Ikada } \\
\text { Monas Amien Rais } \\
\text { Sebut Solo Kumuh, } \\
\text { Gelap, Miskin }\end{array}$ & $\begin{array}{l}\text { Berdiri di belakang cagub Fauzi } \\
\text { Bowo Amien Rais turun gunung } \\
\text { cawe-cawe di pilkada Jakarta. } \\
\text { Amien serang Jokowi dengan } \\
\text { melontarkan kampanye negatif soal } \\
\text { pembangunan di solo }\end{array}$ \\
\hline 15 & $\begin{array}{l}23 \text { Agustus } \\
2012\end{array}$ & $\begin{array}{l}\text { Nachrowi \& Basuki } \\
\text { Bahas Isu SARA Di } \\
\text { Kantor Panwaslu }\end{array}$ & $\begin{array}{l}\text { Ketua Panwaslu DKI Jakarta } \\
\text { menerangkan kedua pasangan calon } \\
\text { cawagub akan berdialog di kantor } \\
\text { Panwaslu mengenai isu SARA } \\
\text { yang belakangan menyeruak ke } \\
\text { arena Pemilukada }\end{array}$ \\
\hline 16 & 27 Agustus & Cagub main SARA & Budayawan betawi Ridwan Saidi \\
\hline
\end{tabular}




\begin{tabular}{|c|c|c|c|}
\hline & 2012 & $\begin{array}{l}\text { Bakal Rugi Sendiri } \\
\text { Ridwan Saidi: Jakarta } \\
\text { Kota Pluralis }\end{array}$ & $\begin{array}{l}\text { berpendapat bahwa isu SARA tidak } \\
\text { akan berpengaruh banyak pada } \\
\text { putaran dua Pilkada DKI } 2012 \\
\text { mendatang sejak dulu Jakarta } \\
\text { merupakan kota plural yang } \\
\text { penduduknya terdiri dari beragam } \\
\text { etnis, suku, dan agama }\end{array}$ \\
\hline 17 & $\begin{array}{l}28 \text { Agustus } \\
2012\end{array}$ & $\begin{array}{l}\text { Panwas: Tim Sukses } \\
\text { Cagub Penyebar Isu } \\
\text { SARA Akan Ditindak }\end{array}$ & $\begin{array}{l}\text { Panwaslu berjanji akan menindak } \\
\text { dengan tegas apabila terjadi } \\
\text { kampanye di luar jadwal yang } \\
\text { sudah ditetapkan oleh KPU terlebih } \\
\text { dengan cara menghasut, menghina } \\
\text { suku, agama, ras dan antargolongan }\end{array}$ \\
\hline 18 & $\begin{array}{l}29 \text { Agustus } \\
2012\end{array}$ & $\begin{array}{c}\text { Timses Cagub } \\
\text { Penyebar Isu SARA } \\
\text { Diancam Lima Tahun } \\
\text { Penjara }\end{array}$ & $\begin{array}{l}\text { Politisi PAN Alvin Lie tak segan- } \\
\text { segan untuk mengingatkan kepada } \\
\text { timses Foke-Nara agar tidak } \\
\text { menyinggung soal SARA sebab hal } \\
\text { tersebut melanggar UU No } 40 \\
\text { tahun } 2008 \text { tentang penghapusan } \\
\text { diskriminasi dan etnis }\end{array}$ \\
\hline 19 & $\begin{array}{l}31 \text { Agustus } \\
2012\end{array}$ & $\begin{array}{c}\text { Tangkis isu SARA } \\
\text { yang beredar di Jakarta } \\
\text { Politisi Gerindra } \\
\text { terpaksa obral titel } \\
\text { Haji Jokowi }\end{array}$ & $\begin{array}{l}\text { Ketua DPP Partai Gerindra DKI } \\
\text { Jakarta M taufik harus repot-repot } \\
\text { mengobral titel Haji Jokowi untuk } \\
\text { menetralisir isu tersebut }\end{array}$ \\
\hline
\end{tabular}

c) Pemberitaan Surat Kabar Harian Rakyat Merdeka Bulan September 2012

Tabel 6

Pemberitaan Surat Kabar Harian Rakyat Merdeka Bulan September 2012

\begin{tabular}{|c|c|c|c|}
\hline No & Tanggal & Judul & Keterangan \\
\hline 1 & $\begin{array}{c}1 \\
\text { September } \\
2012\end{array}$ & $\begin{array}{c}\text { Siap Duduk Di Satu } \\
\text { Pertemuan Jokowi \& } \\
\text { Foke Sepakati } \\
\text { Kampanye Tanpa Isu } \\
\text { SARA }\end{array}$ & $\begin{array}{l}\text { Ide Taufik Kiemas mempertemukan } \\
\text { dua pasangan cagub-cawagub } \\
\text { Jakarta untuk mendeklarasikan } \\
\text { kampanye anti SARA di putaran } \\
\text { dua Pilkada Jakarta di tanggapi } \\
\text { positif. Jokowi dan Fauzi Bowo } \\
\text { akan duduk satu meja menyepakati } \\
\text { deklarasi tersebut }\end{array}$ \\
\hline 2 & $\begin{array}{c}4 \\
\text { September } \\
2012\end{array}$ & $\begin{array}{l}\text { MUI Pusat Larang } \\
\text { MUI Jakarta Ikutan } \\
\text { Dukung Cagub }\end{array}$ & $\begin{array}{l}\text { Ma'ruf Amin meminta kepada MUI } \\
\text { Jakarta agar tidak mengeluarkan } \\
\text { fatwa dukungan atau dalil apapun } \\
\text { untuk mendukung salah satu } \\
\text { pasangan calon dalam Pilkada DKI } \\
\text { Jakarta }\end{array}$ \\
\hline 3 & $\begin{array}{l}5 \\
\text { September } \\
2012\end{array}$ & $\begin{array}{l}\text { Isu SARA Dibiarkan } \\
\text { Hidup, Kualitas } \\
\text { Pilkada Hancur }\end{array}$ & $\begin{array}{l}\text { Sebagai ketua DPR, Marzuki Ali } \\
\text { disarankan netral di Pilkada Jakarta. } \\
\text { Aktivis kecewa Marzuki terkesan }\end{array}$ \\
\hline
\end{tabular}




\begin{tabular}{|c|c|c|c|}
\hline & & $\begin{array}{l}\text { Dikritik Aktivis, } \\
\text { Marzuki Tak Mau } \\
\text { Buang Tenaga }\end{array}$ & $\begin{array}{l}\text { terlalu semangat "menjual" Fauzi } \\
\text { Bowo }\end{array}$ \\
\hline 4 & $\begin{array}{c}12 \\
\text { September } \\
2012\end{array}$ & $\begin{array}{c}\text { Budayawan Kecam } \\
\text { Foke Tak Ada Alasan } \\
\text { Usir Warga Betawi }\end{array}$ & $\begin{array}{l}\text { Pasangan Foke-Nara dikecam atas } \\
\text { pernyataan saat acara lebaran } \\
\text { Betawi dia mengatakan akan } \\
\text { mencabut KTP dan mempersilahkan } \\
\text { warga Betawi keluar dari Betawi } \\
\text { jika tak memilih orang Betawi }\end{array}$ \\
\hline
\end{tabular}

\section{Kartelisasi Media Massa dengan Partai Politik}

Persoalan media, dari awal media massa memang sudah di blok oleh salah satu calon, Panwaslu DKI Jakarta bersama KPI jangan membuat kampanye sebelum itu, akan tetapi hanya iklan saja misalkan advetorial tidak dijadikan advetorial lalu permainan antara wartawan dan tim sukses dan antara tim sukses dengan dewan redaksi.

\section{Pandangan Para Tokoh DKI Jakarta Terkait Sentimen Keagamaan}

Isu keagamaan adalah isu yang layak jual kemasan jadi bangunannya isu syariat islam dan nasionalisme dengan agama dan pancasila. sejak tahun 1955 sampai skarang sejak pemilu pertama kali isu tersebut tidak akan pernah ada habishabisnya persoalannya adalah apakah kemudian isu agama ini memang isu agama atau hanya kemasan saja karna yang dikhawatirkan itu Cuma kemasan saja kenapa. jadi dalam pemilu-pemilu persoalan agama itu hanya simbol saja atau alat yang digunakan untuk dijadikan per-grup muslim dengan muslim, non muslim dengan non muslim kemudian Syiah, Sunni Ahmadiah atau bukan Ahmadiyah sebenarnya tidak ada relefansinya karena, Pemilukada terkait bagaimana seorang pemimpin punya visi dan misi program dan layak atau bisa memajukan selama lima tahun kedepan Cuma masalahnya seorang pemimpin itu dilihat dari etisnya agamanya dan persoalannya isu dalam pemilukada kemarin.

\section{E. Masa Depan Kartelisasi Media Massa dengan Partai Politik}

Ada banyak hal yang bisa dilihat dari penelitian ini terutama bagaimana media massa melakukan konstruksi berita terkait dengan sentimen keagamaan pada pemilihan umum kepala daerah (Pemilukada) DKI Jakarta. Pada saat pemilihan kepala daerah pencitraan yang akan dinilai berdasarkan baik dan buruk. Baik disini pencitraan yang dilakukan oleh media massa terhadap salah satu calon gubernur 
sesuai dengan fungsi media masa sendiri yang tidak dipengaruhi, maupun oleh pengaruh eksternal dan internal media yang bisa mengkonstruksi media kearah negatif. Media massa diposisikan sebagai salah satu "watch dog” (pengawas) dari sistem kenegaraan yang memiliki nilai demokrasi.

\section{Kesimpulan}

Penelitian yang dilakukan pada media cetak lokal di DKI Jakarta, memperlihatkan hasil yang menarik terkait bagaimana media massa melakukan konstruksi sentimen keagamaan pada massa Pemilukada DKI Jakarta berlangsung. Masing masing media mempunyai faktor yang berbeda selain itu ada beberapa faktor lain yaitu faktor jurnalis walaupun hal ini tidak memiliki keberpihakan tetapi sebagai seorang unsur jurnalis memiliki unsur hegemoni (politik, ideologi, budaya) tidak bisa menafikan ini. Sehingga bisa dikatakan media massa dalam mengkonstruksi pemberitaan sentimen keagamaan pada Pemilukada DKI Jakarta tidak bisa lepas dari berbagai faktor yang melingkupi masing-masing media massa tersebut.

Melihat aspek teoritis, dari penelitian ini tidak bisa dilihat dari satu teori saja tetapi harus juga dilihat dari teori yang lain dan juga mampu melihat wajah media dari berbagai aspek. Pendekatan yang dilakukan hanya pada satu aspek hanya akan menjadikan penelitian ini hampa. Tetapi penelitian yang dilihat dari berbagai aspek akan menjadikan penelitian ini lebih bermakna. Sehingga penelitian yang dilakukan dengan menggunakan analisis isi tidak mampu mengangkat aspek lain yang ada diluar penelitian ini secara maksimal penelitian ini terbatas pada keterlibatan peneliti pada proses pembuatan berita sentimen keagamaan paad pemilukada DKI Jakarta Tersebut 


\section{BLIBIOGRAFI}

Amrullah, F., \& Waryana, W. (2019). Hubungan Keadaan Lingkungan Madrasah Terhadap Sikap Keagamaan Anak di Madrasah Diniyah Takmiliyah Awaliyah Nurul Huda Desa Wirakanan Kec. kandanghaur Kab. Indramayu. Syntax Literate; Jurnal Ilmiah Indonesia, 4(8), 69-78.

Bell, P. (2001). Content analysis of visual images. Handbook of Visual Analysis, 13.

Berger, P. L., \& Luckmann, T. (1991). The social construction of reality: A treatise in the sociology of knowledge. Penguin Uk.

Hamad, I. (2004). Konstruksi realitas politik dalam media massa: Sebuah studi critical discourse analysis terhadap berita-berita politik. Yayasan Obor Indonesia.

Moleong, L. J., \& Surjaman, T. (1991). Metodologi penelitian kualitatif. Penerbit PT Remaja Rosdakarya.

Newman, W. L. (1991). Social research methods: Qualitative and quantitative approaches. Allyn and Bacon.

Nuruzzaman, M. (2018). Terorisme Dan Media Sosial Sisi Gelap Berkembangnya Teknologi Informasi Komunikasi. Syntax Literate; Jurnal Ilmiah Indonesia, 3(9), 61-76. 